\title{
A Two-Factor Model to Investigate the Effect of Time and Location to the Total Consumption Poverty Lines (TCPL) in Zimbabwe
}

\author{
Romeo Mawonike, Blessing Chigunyeni \\ Department of Mathematics and Computer Science, Great Zimbabwe University, Masvingo, Zimbabwe
}

Email address:

rmawonike@yahoo.com (R. Mawonike), bchigunyeni@yahoo.com (B. Chigunyeni)

\section{To cite this article:}

Romeo Mawonike, Blessing Chigunyeni. A Two-Factor Model to Investigate the Effect of Time and Location to the Total Consumption Poverty Lines (TCPL) in Zimbabwe. American Journal of Theoretical and Applied Statistics. Vol. 5, No. 2, 2016, pp. 39-48. doi: 10.11648/j.ajtas.20160502.11

\begin{abstract}
Poverty is rampant throughout the entire country of Zimbabwe and is smelt everywhere as its wave penetrates every sector of the economy. Zimbabwe's poverty is directly linked to its extremely high unemployment rate. Men, women, and youth are all affected by unemployment, including university graduates, as a number of industries and businesses have closed over the years, due to decline in tobacco exports, and the loss of revenue from the mining and farming sectors. Geographical location has a significant role in determining the income one has to spend to earn a living as there is some disparity in total consumption poverty lines with different provinces. Financial assistance or aids also varies in volume with the nature of province. In this paper, we seek to investigate whether Total consumption poverty line in Zimbabwe varies with time (type of month) and or with geographical location (the type of province into which one lives). We further seek to investigate which provinces share the same TCPL and which ones are most affected. We apply an ordinary Two-Factor Factorial Design to conclude our investigation.
\end{abstract}

Keywords: Experimental Design, Total Consumption Poverty Line, Analysis of Variance, Multiple Comparisons

\section{Introduction}

Zimbabwe has in the pas $\mathrm{t} 14$ years has been on the spotlight. Headlines dominated everywhere on the number of challenges that have swept the country to its core. These include: poverty, land reforms, elections, corruption and human migration. All these factors worsened the economy to the extent that everyone in Zimbabwe cries foul for help from international community. Starting back from the late 1990s the country experienced an economic turn down that has windswept livelihood capacities of both the urban and the rural population. The poor are becoming poorer and the rich are surviving on the poor. Each province has different perceptions and definitions about poverty. Therefore, there is confusion among donors and government on which province is poorest and how much to devote in terms of financial assistance and projects to help the suffering communities. Many people hate their provinces wishing if they could be relocated to other provinces because of the deepened poverty in their areas. Cultures and politics in different areas have distorted the knowledge people had on economy and freedom from 1980 to 1990. Some provinces depend on agriculture, some on mining, some on industry and some on trade both local and foreign. As a result, it is difficult to calculate the TCPL for each province and determine who is most affected. Although several analyses have discussed the nature of the crisis from various backgrounds with different emphasis and views, there is lack of agreement to which is the real cause of this crisis. Some authors point to the political arena (lack of leadership) as the main culprit and some are pointing fingers to sanctions by Western countries. Poverty is rampant throughout the entire country and is smelt everywhere as its wave penetrates every sector of the economy. The situation has even exacerbated by shortage of electricity (or no electricity) for house hold and industry consumption.

\section{Significance of the Study}

This research will highlight the effect of time and location on the distribution of poverty lines in Zimbabwe. It will help ordinary people, government and well wishers to have 
knowledge on how poverty lines are distributed across the country as well as knowing the time when TCPL is high or low so that budget cannot be misled. Having the full knowledge on the distribution of poverty lines across provinces, makes it easier for the government and donors to devote more funds and projects to much affected areas to save more lives. In addition, the research will reduce misconception and misrepresentation of information or reliance on old information on TCPL across the whole country.

\section{Overview of the Country}

Zimbabwe is situated in the southern part of Africa. It borders with Mozambique, South Africa, Botswana and Zambia. The country is landlocked with the total area of approximately 390757 square kilometers and its population was 12973808 by 2012 [1]. The Country has an average inter-censual annual population growth of $1.1 \%$ for the period 2002-2012. The population is expected to rise to approximately 14 million by end of 2015 . The country is classified as a low-income country by the World Bank [2].

Zimbabwe is divided into ten (10) provinces of which two namely Harare (Capital city) and Bulawayo (second largest) are urban provinces whilst the rest are mixed (urban and rural). Agriculture is the back bone of Zimbabwean economy. Most of the agriculture depend on natural rainfall and the economy is susceptible to weather or climate variations that include droughts and floods.

Zimbabwe's formal education system is divided into primary, secondary and tertiary schools. Health sector consist of primary level care provided by clinics, secondary care provided by district hospital sand tertiary services provided by provincial and general or referral hospitals [1].

Zimbabwe as a country suffers from many challenges due to its location and human errors: firstly, as a landlocked country, Zimbabwe lacks direct access to sea ports. Secondly, it is prone to droughts, which have severe negative impacts on commercial agriculture and on subsistence farming as the crop harvests are reduced. Thirdly, it suffers significant deforestation and environmental degradation from poor mining practices. Fourthly, the high prevalence of HIV/AIDS has created a labour shortage, increased healthcare costs, and significantly curtailed life expectancy to 44 years [3]. A further vulnerability is the lack of good leadership, which plays a role in the rife and widespread poverty through some divisive policies. Poor leadership has also led to dissolution infrastructure and to rising criminal activity.

\section{Historical Background and Literature}

Total consumption Poverty Line (TCPL) is derived by computing the non-food consumption expenditures of households whose total expenditures per capita just equal the value of the Food Poverty Line (FPL) [1]. Poverty is "the state or condition of having little or no money, goods, or means of support; condition of being poor; indigence" while absolute poverty is defined as "the lack of the basic elements needed for human survival: food, water, proper clothing, and shelter [4]. Poverty is considered a basic deprivation of wellbeing to live comfortably, see [4], for example, lack of adequate food, shelter, education, health facilities, and prone to natural disasters such as floods and droughts. Zimbabwean government uses total consumption poverty line as an instrument to measure poverty [5]. TCPL represents the total income needed for five members of a household as a minimum for them not to be deemed poor [1]. The TCPL in Zimbabwe is pegged at US\$462 per five people per month, which means that $77 \%$ of the population is living below the poverty datum line [1].

There are five dimensions of poverty discovered in [6] and [7] namely: lack of adequate income or assets for income generation; physical weakness as a result of under-nutrition, disability or sickness; physical or social isolation that affects access to goods and services; vulnerability to risks; and 'noiselessness' or elimination from decision-making processes within the existing economic, political, cultural and social cycles. Hence, poverty has many dimensions that interact and reinforce each other in very complex ways [8]. There is, for instance, a close correlation between low education levels of the poor and their low income; both reinforcing each other in ways that perpetuate poverty [9]. In addition, low education levels can reinforce the exclusion of the poor from participating in decision-making processes that affect their lives, making the poor both voiceless and powerless [10].

There are several methods for setting poverty lines and they include: the Human Development Index (HDI); the Food Energy Intake Approach; the Cost of Basic Needs Approach (conventional approach); the US\$1/day per person criterion (now adjusted to US\$1.25/day per person) that is often used for international comparisons; and a Social Subjective Poverty Line [11], [12]. Another international poverty measure used specifically to determine water poverty is the Water Poverty Index (WPI) [13]. Poverty measures based on income or consumption have their associated challenges as survey designs vary between countries and overtime, making country comparisons difficult [2], [14]. Most countries have two poverty lines [2], [7]: a) food poverty line, based only on the income needed for sufficient calories or based on prevailing consumption patterns of a basket of basic goods (sometimes called the extreme poverty line); and b) a poverty line that makes an allowance for the costs of non-food needs. The choice of a poverty line is crucial when analyzing the poverty status, as it determines the outcomes of poverty comparisons [10].

There have been two broad types of poverty studies at national level in Zimbabwe. The first type has concerned itself with determining the level of income or consumption below which a household is deemed poor [1]. These studies construct a poverty datum line (PDL) and households whose incomes and consumptions fall below this line are deemed poor. The second study begins by constructing a PDL and uses it to measure and analyze poverty by examining the 
characteristics of poor households.

Zimbabwe's unemployment rate has risen to $94 \%$ in 2007 ; meaning that less than half a million people in the country are formally employed [15]. This unemployment rate rose to $95 \%$ in 2010 and it is still very high. This translates to very few adults earning a formal income, with less than 1 in 10 Zimbabweans being employed. Zimbabwe's poverty is therefore directly linked to its extremely high unemployment rate. Men, women and youth are all affected by unemployment, including university graduates, as numerous businesses have closed over the years, following the decline in tobacco exports, and the loss of revenue from the mining and farming sectors. Many of the graduates are seeking employment, further training, and educational opportunities, at home and abroad. Therefore, the earnings of local businesses decline because there is less spending and the country's overall Gross Domestic Product (GDP) decreases further as there are fewer goods and services being produced. Lack of diversified industries is due to economic conditions; make it difficult to obtain loans or credit.

Furthermore, the current political climate does not prompt confidence from investors. The government's implementation of land reforms and resettlement has backfired, and the lack of industry diversification has become the proverbial shackle around Zimbabwe's neck over the last decade, since the economic decline resulted in the closure of many businesses. Food insecurity is now a major peril factor for Zimbabwe. The elevated price of imported foods means that many Zimbabweans now go without enough meals. Regrettably, those adults living with HIV/AIDS are too weak to work or grow their own food, and too poor to buy the anti-retroviral medicine that they need [16].

Poverty rates in Zimbabwe also vary among provinces. Matabeleland North province has the highest poverty rate in Zimbabwe with $70 \%$ of its people classified as extremely poor. It is also intense in the South Eastern provinces of Manicaland and Masvingo which are among the driest and less productive areas in the country [17]. Poverty is increasing in Binga District in Matabeleland North despite the intervention by Non-Governmental organizations (NGOs). The reason is due to lack of infrastructure like roads, shortage of schools leading to high illiteracy level, lack of clean water and high unemployment levels [17]. NGOs have implemented various poverty alleviation projects in most of the poorest provinces in Zimbabwe but these provinces are still suffering a lot because of political instability which has serious adverse impact on their operation [17]. With the deepening of poverty in Zimbabwe the government and the civil society sector have therefore responded with some strategies to deal with it. There is need for community involvement in decision making, project ownership, and clear lines of communication with the NGOs, among others [17]. Linking project members with relevant institutions and training, ensures sustainability of community projects and community empowerment towards poverty eradication [18]. The theory of geographical disparities asserts that people, institutions as well as cultures in particular areas lack the objective resources that are required to generate well-being as well as income, and that they also lack the power to claim redistribution [19]. This theory suggests that poverty is determined by closeness to natural resources, disinvestment, density and diffusion of innovation [20].

Housing in poor rural areas consists of mud constructions interspersed with brick, having either thatched roofs or roofs made of wood or tin. These houses have no running water or electricity, and about $63 \%$ of the rural population has insufficient sanitation facilities [3]. On the other hand, urban dwellings are built of brick and generally have electricity, running water and modern sanitation. Recent positive signs in housing include an initiative by Housing Cooperative Schemes to upgrade informal settlements in most parts of urban areas. These cooperatives develop land for houses, clinics and schools and sell the stands to the community at affordable installments [3].

This paper seeks to investigate the effect of location in terms of province and time (month) to the Total Consumption Poverty Line (TCPL) in Zimbabwe. We seek to provide insights into important questions such as:

- How does the location (province) affect the TCPL?

- How does time (month) affect the TCPL?

- How do both location and time affect the TCPL?

\section{Methodology}

\subsection{Research Data}

Data on total consumption poverty line (TCPL) in US Dollars per person per month was collected from all 10 provinces in Zimbabwe through survey by Zimbabwe National Statistics Agency (ZIMSTAT). The period expands from January 2009 to December 2014 (monthly). The provinces are as follows: Harare (Capital city), Bulawayo, Masvingo, Matabeleland North, Matabeleland South, Manicaland, Mashonaland East, Mashonaland Central, Mashonaland West and Midlands. Therefore, we considered location (province) and month as two factors affecting the TCPL. Type of province and type of month were considered as factor levels. Therefore, in our study, we have considered month as Factor A with factor levels (January, February, March, April, May, June, July, August, September, October, November and December) and Province as Factor B with factor levels (Harare, Bulawayo, Masvingo, Matabeleland North, Matabeleland South, Manicaland, Mashonaland East, Mashonaland Central, Mashonaland West and Midlands).

\subsection{Two-Factor Factorial Design}

The observations are described by a linear statistical model:

$$
y_{i j k}=\mu+\tau_{i}+\beta_{j}+(\tau \beta)_{i j}+\epsilon_{i j k}\left\{\begin{array}{l}
i=1,2, \ldots, a \\
j=1,2, \ldots, b \\
k=1,2, \ldots, n
\end{array}\right.
$$

Where: 
$y_{i j k}$ is the response with factor $\mathrm{A}$ at level $i$ and factor $\mathrm{B}$ with level $j$,

$\mu$ is the mean response,

$\tau_{i}$ is the $i^{\text {th }}$ factor A effect,

$\beta_{j}$ is the $j^{\text {th }}$ factor B effect,

$(\tau \beta)_{i j}$ is the $(i, j)^{t h} A * B$ interaction effect,

$\epsilon_{i j k}$ is the random error of the $k^{\text {th }}$ observation from the $(i, j)^{t h}$ cell.

Assumptions of the model are:

- The model is a fixed effects model.

- $\epsilon_{\mathrm{ijk}} \sim \operatorname{NID}\left(0, \sigma^{2}\right)$

- $\sum_{\mathrm{i}=1}^{\mathrm{a}} \tau_{\mathrm{i}}=\sum_{\mathrm{j}=1}^{\mathrm{b}} \beta_{\mathrm{j}}=\sum_{\mathrm{i}=1}^{\mathrm{a}}(\tau \beta)_{\mathrm{ij}}=\sum_{\mathrm{j}=1}^{\mathrm{b}}(\tau \beta)_{\mathrm{ij}}=0$.

We estimate parameters by minimizing the square errors as follows;

Minimize:

$$
\epsilon_{i j k}^{2}=\sum_{i=1}^{a} \sum_{j=1}^{b} \sum_{k=1}^{n}\left(y_{i j k}-\hat{\mu}-\widehat{\tau}_{l}-\widehat{\beta}_{J}-\left(\widehat{\tau \beta)_{l \jmath}}\right)^{2}\right.
$$

Subject to:

$$
\sum_{i=1}^{a} \tau_{i}=\sum_{j=1}^{b} \beta_{j}=\sum_{i=1}^{a}(\tau \beta)_{i j}=\sum_{j=1}^{b}(\tau \beta)_{i j}=0 .
$$

Solving equation (2) we obtain unique solutions as follows:

$$
\begin{gathered}
\hat{\mu}=\bar{y}_{\ldots,} \quad \hat{\tau}_{i}=\bar{y}_{i . .}-\bar{y}_{\ldots,} \quad i=1,2, \ldots, a \\
\hat{\beta}_{i}=\bar{y}_{. j .}-\bar{y}_{\ldots,}, \quad j=1,2, \ldots, b \\
\widehat{(\tau \beta)}_{i j}=\bar{y}_{i j .}-\bar{y}_{i . .}-\bar{y}_{. j .}+\bar{y}_{. . .}, \begin{array}{l}
i=1,2, \ldots, a \\
j=1,2, \ldots, b
\end{array}
\end{gathered}
$$

Using equation (3), we can find the fitted values $\hat{y}_{i j k}$ as follows:

$$
\begin{aligned}
\hat{y}_{i j k} & =\hat{\mu}+\widehat{\tau}_{\imath}+\widehat{\beta}_{J}+\widehat{(\tau \beta)_{l j}} \\
& =\bar{y}_{\ldots .}+\left(\bar{y}_{i . .}-\bar{y}_{\ldots .}\right)+\left(\bar{y}_{. j .}-\bar{y}_{\ldots .}\right)+\left(\bar{y}_{i j .}-\bar{y}_{i . .}-\bar{y}_{. j .}+\bar{y}_{\ldots}\right) \\
& =\bar{y}_{i j .}
\end{aligned}
$$

We can obtain residuals of the two-factor factorial design using equation (4), that is,

$$
\epsilon_{i j k}=y_{i j k}-\hat{y}_{i j k}=y_{i j k}-\bar{y}_{i j .}\left\{\begin{array}{l}
i=1,2, \ldots, a \\
j=1,2, \ldots, b \\
k=1,2, \ldots, n
\end{array}\right.
$$

Table 1. Field layout of a two-factor design.

\begin{tabular}{l|lll|l}
\hline \multicolumn{1}{c}{ Factor B } \\
\hline
\end{tabular}

We are interested in testing the following hypotheses;

- The strength of factor A treatment effect.

$$
\begin{aligned}
& H_{0}: \tau_{1}=\tau_{2}=\cdots=\tau_{a} \\
& H_{1}: \text { at least one } \tau_{i} \neq 0
\end{aligned}
$$

- The strength of factor B treatment effect.

$$
\begin{gathered}
H_{0}: \beta_{1}=\beta_{2}=\cdots=\beta_{b} \\
H_{1}: \text { at least one } \beta_{j} \neq 0
\end{gathered}
$$

- The interaction of $\mathrm{A}$ and $\mathrm{B}$.

$$
\begin{gathered}
H_{0}:(\tau \beta)_{i j}=0 \\
H_{1}: \text { at least one }(\tau \beta)_{i j} \neq 0
\end{gathered}
$$

\subsubsection{Statistical Analysis of the Fixed Effects Model}

$$
y_{i . .}=\sum_{j=1}^{b} \sum_{k=1}^{n} y_{i j k}, \overline{y_{l . .}}=\frac{y_{i . .}}{b n}, \quad i=1,2,3, \ldots, a
$$

$$
\begin{gathered}
y_{. j .}=\sum_{i=1}^{a} \sum_{k=1}^{n} y_{i j k}, \overline{y_{. j .}}=\frac{y_{. j .}}{a n}, j=1,2,3, \ldots, b \\
y_{i j .}=\sum_{k=1}^{n} y_{i j k}, \overline{y_{l J .}}=\frac{y_{i j .}}{n},\left\{\begin{array}{l}
i=1,2,3, \ldots, a \\
j=1,2,3, \ldots, b
\end{array}\right. \\
y_{\ldots}=\sum_{i=1}^{a} \sum_{j=1}^{b} \sum_{k=1}^{n} y_{i j k}, \overline{y_{. .}}=\frac{y_{\ldots .}}{a b n}\left\{\begin{array}{l}
i=1,2,3, \ldots, a \\
j=1,2,3, \ldots, b \\
k=1,2,3, \ldots, n
\end{array}\right.
\end{gathered}
$$

Where: $a$ is the number of factor levels of factor $A, b$ is the number of factor levels of factor $B$ and $n$ is the number of replications of $(i, j)$ th observation.

\section{Decomposition of the total sum of squares}

$$
\begin{gathered}
\sum_{i=1}^{a} \sum_{j=1}^{b} \sum_{k=1}^{n}\left(y_{i j k}-\bar{y}_{\ldots}\right)^{2}=b n \sum_{i=1}^{a}\left(\bar{y}_{i . .}-\bar{y}_{. . .}\right)^{2} \\
+a n \sum_{j=1}^{b}\left(\bar{y}_{. j .}-\bar{y}_{. .}\right)^{2}+n \sum_{i=1}^{a} \sum_{j=1}^{b}\left(\bar{y}_{i j .}-\bar{y}_{i . .}-\bar{y}_{. j .}+\bar{y}_{\ldots .}\right)^{2}
\end{gathered}
$$




$$
+\sum_{i=1}^{a} \sum_{j=1}^{b} \sum_{k=1}^{n}\left(y_{i j k}-\bar{y}_{i j .}\right)^{2}
$$

This equation can be written in symbolic form as;

$$
S S_{T}=S S_{A}+S S_{B}+S S_{A B}+S S_{E}
$$

Equation (13) can be reduced to a simpler form and formulas for sum of squares are computed assuming the two factor model is balanced.

$$
\begin{gathered}
S S_{T}=\sum_{i=1}^{a} \sum_{j=1}^{b} \sum_{k=1}^{n} y_{i j k}^{2}-\frac{y_{\ldots .}^{2}}{a b n} \\
S S_{A}=\sum_{i=1}^{a} \frac{y_{i . .}^{2}}{b n}-\frac{y_{\ldots .}^{2}}{a b n} \\
S S_{B}=\sum_{j=1}^{b} \frac{y_{. j .}^{2}}{a n}-\frac{y_{\ldots .}^{2}}{a b n} \\
S S_{A B}=\sum_{i=1}^{a} \sum_{j=1}^{b} \frac{y_{i j .}^{2}}{n}-\frac{y_{\ldots .}^{2}}{a b n}-S S_{A}-S S_{B}
\end{gathered}
$$

Degrees of freedom for sum of squares are given below:

Table 2. Degrees of freedom.

\begin{tabular}{ll}
\hline Effect & Degrees of freedom \\
\hline$A$ & $a-1$ \\
$B$ & $b-1$ \\
AB Interaction & $(a-1)(b-1)$ \\
Errors & $a b(n-1)$ \\
Total & $a b n-1$ \\
\hline
\end{tabular}

Each sum of square divided by its degrees of freedom is a mean square [20]. The expected values of the mean square are:

$$
\begin{aligned}
& E\left(M S_{A}\right)=E\left(\frac{S S_{A}}{a-1}\right)=\sigma^{2}+\frac{b n \sum_{i=1}^{a} \tau_{i}^{2}}{a-1} \\
& E\left(M S_{B}\right)=E\left(\frac{S S_{B}}{b-1}\right)=\sigma^{2}+\frac{a n \sum_{j=1}^{b} \beta_{j}^{2}}{b-1} \\
& E\left(M S_{A B}\right)=E\left(\frac{S S_{A B}}{(a-1)(b-1)}\right)=\sigma^{2}+\frac{n \sum_{i=1}^{a} \sum_{j=1}^{b}(\tau \beta)_{i j}^{2}}{(a-1)(b-1)} \\
& E\left(M S_{E}\right)=E\left(\frac{S S_{E}}{a b(n-1)}\right)=\sigma^{2}
\end{aligned}
$$

Table 3. Analysis of Variance for two-factor design.

\begin{tabular}{lllll}
\hline Source of Variation & Sum of Squares & Degrees of Freedom & Mean Square & $\boldsymbol{F}_{\mathbf{0}}$ \\
\hline A Treatment & $S S_{A}$ & $a-1$ & $\frac{S S_{A}}{a-1}$ & $\frac{S S_{B}}{b-1}$ \\
B Treatment & $S S_{B}$ & $b-1$ & $\frac{S S_{A B}}{(a-1)(b-1)}$ & $F_{0}=\frac{M S_{A}}{M S_{E}}$ \\
AB Interaction & $S S_{A B}$ & $(a-1)(b-1)$ & $\frac{S S_{E}}{a b(n-1)}$ & $F_{0}=\frac{M S_{B}}{M S_{E}}$ \\
Error & $S S_{E}$ & $a b(n-1)$ & & \\
Total & $S S_{T}$ & $a b n-1$ & \\
\hline
\end{tabular}

Table 3 was taken from Montgomery $5^{\text {th }}$ Edition: Design and Analysis of Experiments. 2001. Pg180.

\subsubsection{Multiple Comparisons}

When analysis of variance indicates that the column or row means differ, it is usually of interest to make comparisons between individuals row or column means to discover the specific differences [20]. We are going to apply the Turkey's test to our problem, but this will only happen if the null hypothesis is rejected on factor A and or factor B. We compare the Least Significant Difference (LSD) against the difference between any two rows or column means. The LSD is given by: $t_{(a-1)(b-1)}^{\alpha} \sqrt{\frac{2 M S E}{n}}$.

\subsubsection{Model Diagnostic Checking}

We check the adequacy of the model before any conclusion is made. We validate the assumptions in equation (2). Residuals obtained by equation (5) are to be analyzed using the 4-plots that is: residuals against fitted values, normal probability plot, plot residuals against Factor A and plot residuals against Factor B.

\subsubsection{The Research Design}

We have used the Two - Factor Factorial design on the data acquired. Factor $\mathrm{A}$ is being considered as time given by Month with factor levels regarded as months of the year from January to December. Factor B is the location given by Province, factor levels of B are the provinces in Zimbabwe and we have ten provinces. Since the period considered spans from January 2009 to December 2014, each month appears six (6) times in each province. That is 6 becomes the number of replications of each basic experiment and in total we have 720 data points.

\section{Data Analysis and Results}

\subsection{The Design of a Two-Factor Model}

Table 4 shows the design of a Two-Factor Model with 720 data points. Each factor level of the factor Month appears 6 times in each province. 
Table 4. Field layout of the design.

\begin{tabular}{|c|c|c|c|c|c|c|c|c|c|c|c|}
\hline & & & & & & Province & & & & & \\
\hline & & Bulawayo & Manicaland & MashCentral & MashEast & MashWest & MatNorth & MatSouth & Midlands & Masvingo & Harare \\
\hline \multirow{36}{*}{ Month } & \multirow[t]{3}{*}{ Jan } & $103.1,92.5$ & $110.1,86.2$ & $107.2,77.2$ & $117.4,86.08$ & $115.5,87.3$ & $126.2,103.1$ & $108.5,100.0$ & $109.7,89.0$ & $110.4,97.6$ & $98.4,89.4$ \\
\hline & & $100.1,96.2$ & $92.2,87.8$ & $96.5,91.7$ & $97.1,93.6$ & $96.4,96.4$ & $111.7,107.8$ & $107.9,106.0$ & $97.8,91.4$ & $100.2,96.1$ & $101.3,92.8$ \\
\hline & & $98.2,102,3$ & $89.0,93.8$ & $97.0,95.0$ & $86.3,95.5$ & $94.6,101.9$ & $116.4,128.1$ & $119.3,116.1$ & $94.6,95.1$ & $101.5,100.3$ & $101.5,99.1$ \\
\hline & \multirow[t]{3}{*}{ Feb } & $101.8,92.0$ & $80.2,90.6$ & $86.6,84.5$ & $95.3,86.4$ & $88.6,91.9$ & $114.0,101.4$ & $110.3,102.8$ & $118.3,97.1$ & $106.2,99.5$ & $96.5,91.1$ \\
\hline & & $99.1,102,8$ & $97.9,89.9$ & $96.4,93.4$ & $98.7,95.0$ & $98.5,97.1$ & $116.5,108.6$ & $104.0,105.6$ & $100.8,93.6$ & $100.7,98.7$ & $100.6,93.9$ \\
\hline & & $98.9,102.1$ & $90.1,93.6$ & $97.0,94.8$ & $90.8,95.3$ & $98.0,101.7$ & $132.1,127.9$ & $122.0,115.9$ & $92.1,94.9$ & $101.5,100.1$ & $110.8,98.9$ \\
\hline & \multirow[t]{3}{*}{ Mar } & $83.7,90.8$ & $94.5,90.7$ & $78.3,87.1$ & $91.2,91.9$ & $83.8,96.0$ & $108.2,99.2$ & $103.9,93.6$ & $94.1,93.0$ & $92.9,94.2$ & $96.0,90.6$ \\
\hline & & $95.8,96.6$ & $94.0,90.4$ & $95.3,94.5$ & $96.9,97.2$ & $97.6,100.0$ & $110.4,97.2$ & $104.9,103.6$ & $97.5,96.5$ & $99.1,104.1$ & $99.1,95.0$ \\
\hline & & $100.6,102.2$ & $93.0,92.9$ & $95.7,95.5$ & $90.1,93.4$ & $100.0,101.7$ & $129.8,130.9$ & $124.4,115.0$ & $95.2,93.8$ & $100.5,98.1$ & $110.4,97.6$ \\
\hline & \multirow[t]{3}{*}{ Apr } & $80.8,101.1$ & $89.4,95.3$ & $77.2,97.6$ & $88.4,91.1$ & $83.7,98.2$ & $98.7,109.4$ & $88.1,95.0$ & $88.6,100.7$ & $88.2,105.1$ & $94.0,94.9$ \\
\hline & & $97.9,101.8$ & $92.7,117.8$ & $95.3,111.3$ & $95.9,113.8$ & $96.4,123.4$ & $108.0,129.5$ & $104.8,115.0$ & $98.1,99.1$ & $102.9,108.6$ & $95.4,125.1$ \\
\hline & & $100.5,102.1$ & $93.1,93.4$ & $94.9,96.2$ & $87.1,92.5$ & $100.1,100.9$ & $125.6,130.5$ & $122.4,116.8$ & $94.4,93.7$ & $100.0,97.1$ & $103.7,96.7$ \\
\hline & \multirow[t]{3}{*}{ May } & $89.1,102.5$ & $81.5,93.9$ & $81.9,104.0$ & $81.5,89.3$ & $79.6,102.6$ & $85.8,111.4$ & $86.6,106.7$ & $81.6,95.8$ & $85.1,101.4$ & $83.9,101.0$ \\
\hline & & $96.2,101.2$ & $93.2,110.6$ & $97.0,109.3$ & $96.2,115.4$ & $98.7,123.3$ & $111.9,126.4$ & $106.2,128.6$ & $97.6,101.8$ & $105.9,108.3$ & $94.4,115.8$ \\
\hline & & $99.7,102.0$ & $92.4,95.0$ & $95.0,98.4$ & $87.0,92.7$ & $98.7,102.0$ & $122.5,129.9$ & $117.2,115.6$ & $95.5,94.3$ & $98.7,97.6$ & $102.1,97.4$ \\
\hline & \multirow[t]{3}{*}{ Jun } & $86.9,116.5$ & $83.6,96.6$ & $82.3,95.0$ & $87.1,100.5$ & $81.2,101.6$ & $88.4,114.2$ & $87.2,99.8$ & $83.7,103.8$ & $89.0,105.2$ & $90.2,103.5$ \\
\hline & & $94.7,96.9$ & $87.2,108.7$ & $89.6,105.1$ & $89.9,102.6$ & $91.4,116.4$ & $98.8,125.2$ & $109.8,127.9$ & $90.2,111.8$ & $99.5,105.0$ & $92.2,111.4$ \\
\hline & & $100.3,101.9$ & $91.8,95.1$ & $94.6,98.3$ & $87.5,96.4$ & $97.7,107.0$ & $131.3,126.7$ & $115.8,120.3$ & $94.0,94.4$ & $98.6,96.2$ & $102.6,97.7$ \\
\hline & \multirow[t]{3}{*}{ Jul } & $93.6,108.8$ & $81.8,94.0$ & $91.4,97.1$ & $88.6,100.5$ & $90.3,98.9$ & $93.7,108.5$ & $94.1,101.9$ & $85.6,96.5$ & $93.5,102.7$ & $88.8,99.4$ \\
\hline & & $95.4,93.0$ & $93.2,106.6$ & $90.2,104.8$ & $89.9,104.3$ & $91.4,103.2$ & $98.8,123.8$ & $102.4,124.6$ & $90.4,105.7$ & $100.6,111.4$ & $92.6,108.3$ \\
\hline & & $100.0,101.6$ & $91.9,94.2$ & $94.1,97.4$ & $92.2,95.3$ & $100.9,104.4$ & $122.2,124.5$ & $111.6,118.7$ & $92.7,92.4$ & $98.0,96.3$ & $101.2,98.4$ \\
\hline & \multirow[t]{3}{*}{ Aug } & $95.2,106.0$ & $88.5,83.9$ & $88.4,86.7$ & $90.5,95.2$ & $91.3,91.44$ & $103.3,103.8$ & $97.9,101.4$ & $86.1,93.3$ & $91.1,95.2$ & $88.2,99.6$ \\
\hline & & $109.1,94.6$ & $102.5,106.6$ & $105.4,104.6$ & $102.3,109.5$ & $101.0,110.4$ & $111.7,121.6$ & $112.2,120.6$ & $107.3,103.8$ & $104.6,112.0$ & $107.7,113.1$ \\
\hline & & $98.7,100.9$ & $91.6,92.6$ & $91.8,97.9$ & $91.0,94.0$ & $98.8,100.9$ & $126.8,122.9$ & $115.2,119.3$ & $93.1,91.1$ & $96.2,95.4$ & $102.6,97.1$ \\
\hline & \multirow[t]{3}{*}{ Sep } & $89.5,101.1$ & $82.1,84.9$ & $84.1,90.8$ & $91.2,96.8$ & $83.2,90.9$ & $98.5,102.2$ & $97.0,103.1$ & $85.9,94.2$ & $92.7,92.5$ & $88.4,93.4$ \\
\hline & & $95.3,95.1$ & $88.7,119.4$ & $90.5,107.2$ & $92.8,114.4$ & $91.2,113.1$ & $104.6,128.8$ & $102.2,125.8$ & $92.1,102.5$ & $95.4,109.2$ & $92.9,118.8$ \\
\hline & & $116.3,101.2$ & $91.7,92.5$ & $93.9,97.7$ & $90.9,94.0$ & $97.2,100.7$ & $122.8,122.8$ & $114.8,118.8$ & $91.3,91.0$ & $96.4,95.2$ & $101.2,96.9$ \\
\hline & \multirow[t]{3}{*}{ Oct } & $95.9,101.0$ & $82.2,82.2$ & $78.5,84.7$ & $88.4,97.6$ & $87.2,86.5$ & $110.7,96.8$ & $98.1,102.1$ & $86.3,92.2$ & $88.4,90.4$ & $90.7,92.9$ \\
\hline & & $97.8,120.7$ & $89.7,104.2$ & $87.9,105.0$ & $92.1,106.3$ & $90.4,112.3$ & $99.7,126.8$ & $103.3,133.0$ & $91.0,119.7$ & $90.7,116.9$ & $93.6,122.5$ \\
\hline & & $99.8,100.4$ & $89.7,91.2$ & $91.7,97.2$ & $91.0,93.9$ & $96.7,100.7$ & $126.0,124.2$ & $114.6,117.9$ & $93.1,89.8$ & $97.0,94.7$ & $101.0,95.6$ \\
\hline & \multirow[t]{3}{*}{ Nov } & $88.1,102.2$ & $77.1,90.4$ & $79.6,85.4$ & $89.3,97.4$ & $84.5,87.8$ & $92.4,104.4$ & $92.5,102.5$ & $78.4,90.2$ & $86.7,91.6$ & $84.4,93.0$ \\
\hline & & $99.0,124.8$ & $89.7,112.0$ & $85.4,106.7$ & $91.5,109.8$ & $94.0,114.2$ & $100.0,125.7$ & $101.7,131.7$ & $91.3,114.8$ & $94.3,126.7$ & $95.1,125.7$ \\
\hline & & $101.0,101.7$ & $90.9,90.0$ & $94.8,97.9$ & $91.7,92.8$ & $97.8,99.0$ & $127.1,122.5$ & $114.3,119.6$ & $93.5,90.5$ & $96.5,94.3$ & $100.8,96.5$ \\
\hline & \multirow[t]{3}{*}{ Dec } & $89.1,95.2$ & $78.2,90.5$ & $73.8,86.1$ & $82.8,97.2$ & $86.3,91.2$ & $99.5,101.5$ & $98.0,99.2$ & $83.1,88.2$ & $92.3,94.7$ & $85.6,91.1$ \\
\hline & & $98.0,103.5$ & $86.5,90.8$ & $88.4,95.6$ & $90.1,87.7$ & $94.4,99.3$ & $100.3,150.1$ & $102.7,127.7$ & $91.5,93.5$ & $90.1,92.9$ & $92.0,104.0$ \\
\hline & & $101.9,101.8$ & $91.7,90.1$ & $96.2,97.9$ & $93.9,92.8$ & $98.4,99.0$ & $127.5,122.6$ & $114.7,119.6$ & $94.3,90.5$ & $97.5,94.4$ & $99.9,96.5$ \\
\hline
\end{tabular}

\subsection{Analysis of Variance (ANOVA)}

Table 5. ANOVA Table.

\begin{tabular}{llllll}
\hline Analysis of variance & \multicolumn{5}{l}{} \\
\hline Variate: TCPL & & & & & \\
\hline Source of variation & d.f. & s.s. & m.s. & v.r. & F pr. \\
\hline Month & 11 & 949.93 & 86.36 & 0.95 & 0.491 \\
Province & 9 & 32847.38 & 3649.71 & 40.17 & $<.001$ \\
Month. Province & 99 & 1851.63 & 18.70 & 0.21 & 1.000 \\
Residual & 600 & 54517.58 & 90.86 & & \\
Total & 719 & 90166.53 & & & \\
\hline
\end{tabular}

Table 5 above shows a 3-way ANOVA table for two factors. The results show that the null hypothesis in equation
(6) is accepted, meaning that the difference in TCPL regarding different months is insignificant, that is TCPL is the same in all months of the year. On the other hand, the null hypothesis in (7) is rejected, explaining that the TCPL is regarded as different in some of the provinces in Zimbabwe. Finally, the null hypothesis of the interaction between Month and Province is accepted, meaning that the distribution of TCPL across the country is not affected by the interaction of Month and Province.

\subsection{Multiple Comparisons of the Provinces}

We have to do pair wise comparison in the provinces since we have rejected the null hypothesis from the ANOVA table above.

Table 6. TCPL monthly means.

\begin{tabular}{lllllll}
\hline Month & January & February & March & April & May & June \\
\hline Mean & 100.03 & 99.93 & 97.82 & 100.67 & 100.28 \\
Month & July & August & September & October & November & December \\
Mean & 99.47 & 100.92 & 99.17 & 99.04 & 99.09 & 96.73 \\
\hline
\end{tabular}


Table 7. TCPL Provincial means.

\begin{tabular}{llllll}
\hline Province & Harare & Bulawayo & Masvingo & Midlands & Manicaland \\
\hline Mean & 98.81 & 99.28 & 98.65 & 94.87 & 92.67 \\
Province & Mashonaland East & Mashonaland West & Mashonaland Central & Matabeleland North & Matabeleland South \\
Mean & 94.91 & 97.62 & 93.52 & 114.48 & 109.60 \\
\hline
\end{tabular}

Table 8. Least significant differences of means.

\begin{tabular}{llll}
\hline \multicolumn{2}{l}{ Least significant differences of means (5\% level) } & & Month \\
\hline \multicolumn{1}{l}{ Table } & Month & Province & \\
\hline Province & & & 6 \\
rep. & 60 & 72 & 600 \\
d.f. & 600 & 600 & $\mathbf{1 0 . 8 0 8}$ \\
\hline l.s.d. & $\mathbf{3 . 4 1 8}$ & $\mathbf{3 . 1 2 0}$ & \\
\hline
\end{tabular}

Using different means in tables 6,7 and 8 , we can find out which provinces have the same TCPL as well as provinces with different TCPL as shown in table 9 below.

Table 9. Pair-wise comparison table of provinces

\begin{tabular}{|c|c|c|c|c|}
\hline Province1 & Province2 & Difference & LSD & Decision \\
\hline Harare & Bulawayo & 0.47 & 3.12 & Equal \\
\hline Harare & Manicaland & 6.14 & 3.12 & Not equal \\
\hline Harare & Mashonaland Central & 5.29 & 3.12 & Not equal \\
\hline Harare & Mashonaland West & 1.19 & 3.12 & Equal \\
\hline Harare & Mashonaland East & 3.9 & 3.12 & Not equal \\
\hline Harare & Masvingo & 0.16 & 3.12 & Equal \\
\hline Harare & Matabeleland North & 15.67 & 3.12 & Not equal \\
\hline Harare & Matabeleland South & 10.79 & 3.12 & Not equal \\
\hline Harare & Midlands & 3.94 & 3.12 & Not equal \\
\hline Bulawayo & Manicaland & 6.61 & 3.12 & Not equal \\
\hline Bulawayo & Mashonaland Central & 5.76 & 3.12 & Not equal \\
\hline Bulawayo & Mashonaland East & 4.37 & 3.12 & Not equal \\
\hline Bulawayo & Mashonaland West & 1.66 & 3.12 & Equal \\
\hline Bulawayo & Masvingo & 0.63 & 3.12 & Equal \\
\hline Bulawayo & Matabeleland North & 15.2 & 3.12 & Not equal \\
\hline Bulawayo & Matabeleland South & 10.32 & 3.12 & Not equal \\
\hline Bulawayo & Midlands & 4.41 & 3.12 & Not equal \\
\hline Manicaland & Mashonaland Central & 0.85 & 3.12 & Equal \\
\hline Manicaland & Mashonaland East & 2.24 & 3.12 & Equal \\
\hline Manicaland & Mashonaland West & 4.95 & 3.12 & Not equal \\
\hline Manicaland & Masvingo & 5.98 & 3.12 & Not equal \\
\hline Manicaland & Matabeleland North & 21.81 & 3.12 & Not equal \\
\hline Manicaland & Matabeleland South & 16.93 & 3.12 & Not equal \\
\hline Manicaland & Midlands & 2.2 & 3.12 & Equal \\
\hline Mashonaland Central & Mashonaland East & 1.39 & 3.12 & Equal \\
\hline Mashonaland Central & Mashonaland West & 4.1 & 3.12 & Not equal \\
\hline Mashonaland Central & Masvingo & 5.13 & 3.12 & Not equal \\
\hline Mashonaland Central & Matabeleland North & 20.96 & 3.12 & Not equal \\
\hline Mashonaland Central & Matabeleland South & 16.08 & 3.12 & Not equal \\
\hline Mashonaland Central & Midlands & 1.35 & 3.12 & Equal \\
\hline Mashonaland East & Mashonaland West & 2.71 & 3.12 & Equal \\
\hline Mashonaland East & Masvingo & 3.74 & 3.12 & Not equal \\
\hline Mashonaland East & Matabeleland North & 19.57 & 3.12 & Not equal \\
\hline Mashonaland East & Matabeleland South & 14.69 & 3.12 & Not equal \\
\hline Mashonaland East & Midlands & 0.04 & 3.12 & Equal \\
\hline Mashonaland West & Masvingo & 1.03 & 3.12 & Equal \\
\hline Mashonaland West & Matabeleland North & 16.86 & 3.12 & Not equal \\
\hline Mashonaland West & Matabeleland South & 11.98 & 3.12 & Not equal \\
\hline Mashonaland West & Midlands & 2.75 & 3.12 & Equal \\
\hline Masvingo & Matabeleland North & 15.83 & 3.12 & Not equal \\
\hline Masvingo & Matabeleland South & 10.95 & 3.12 & Not equal \\
\hline Masvingo & Midlands & 3.78 & 3.12 & Not equal \\
\hline Matabeleland North & Matabeleland South & 4.88 & 3.12 & Not equal \\
\hline Matabeleland North & Midlands & 19.61 & 3.12 & Not equal \\
\hline Matabeleland South & Midlands & 14.73 & 3.12 & Not equal \\
\hline
\end{tabular}



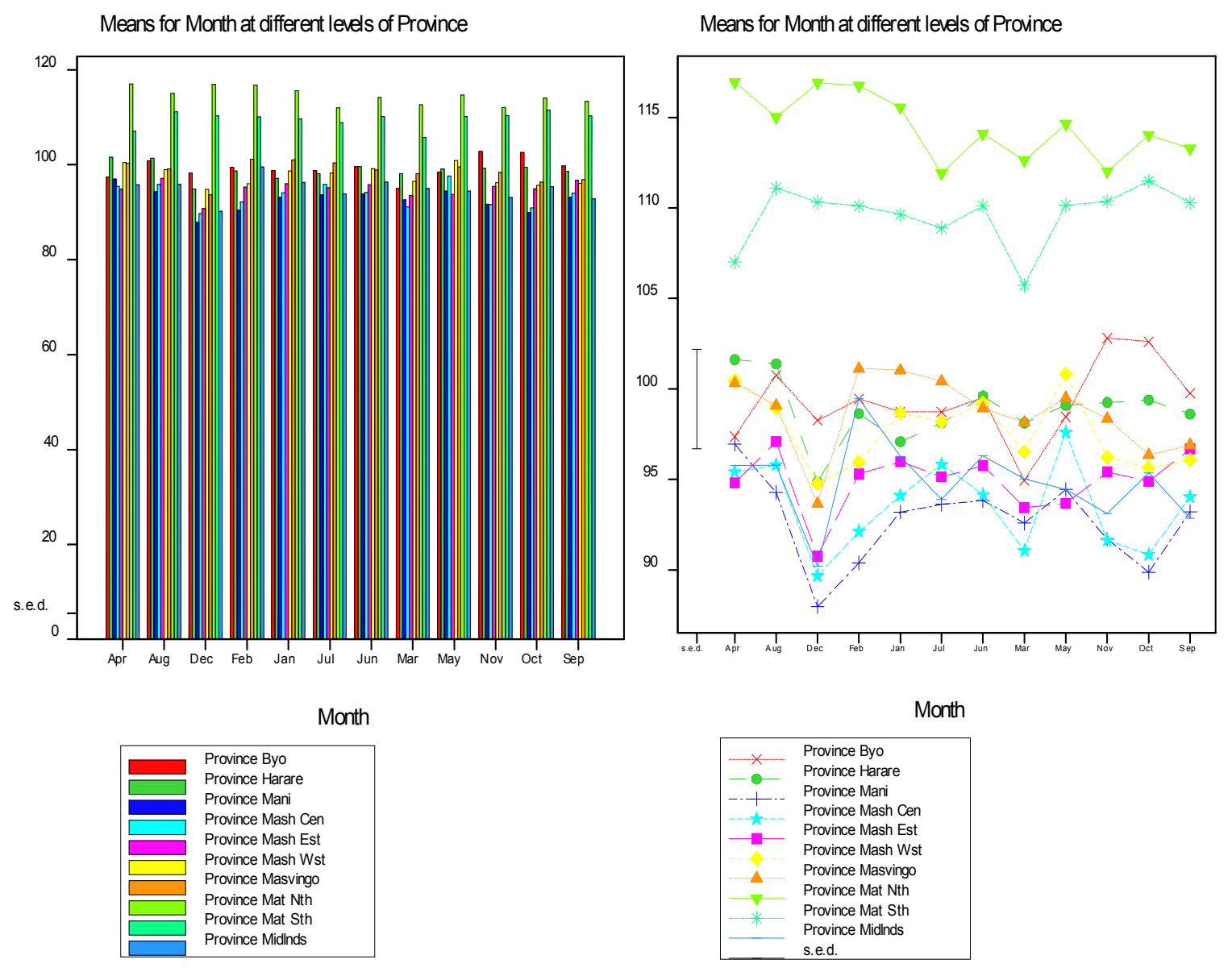

Fig. 1. Means plot months and provinces.

TCPL
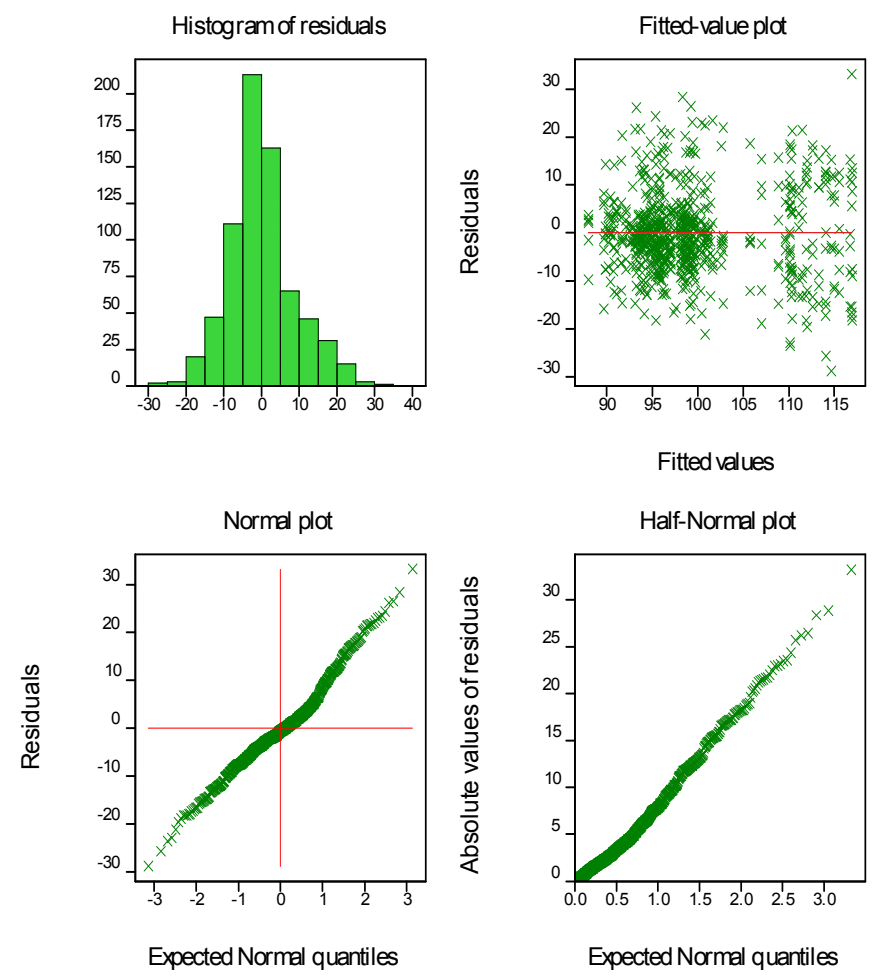

Expected Normal quantiles

Fig. 2. Residual plot. 
Results from table 9 shows that Harare, Bulawayo, Masvingo and Mashonaland West share the same TCPL per person per month while Manicaland, Mashonaland East, Mashonaland Central and Midlands also share the same TCPL. Matabeleland North and Matabeleland South do not have the same TCPL and are as well independent from all other provinces. In addition, Manicaland group records the lowest TCPL followed by Harare group, Matabeleland South, (US\$109.60) is the next and lastly Matabeleland North recording the highest TCPL per person per month, (US\$114.48).

Means plot in fig 1 shows that Matabeleland North has the highest TCPL per person per month for all months recorded from 2009 to 2015, followed by Matabeleland South.

\subsection{Model Diagnostic Checking}

The residual plot in fig 2 shows that the histogram approximates a normal curve, the plot of residuals against fitted values shows that the variance is constant and both normal plots approximate straight lines. Generally, all 4 plots above show that the model is adequate to analyze the data.

\section{Conclusion}

Generally, the type of month has insignificant influence on an increase or decrease of Total Consumption Poverty Line (TCPL) in Zimbabwe. All months of the year have equal role in affecting TCPL per month per person. This means that every person in Zimbabwe is expected to spend equal amount per month throughout the year. On the other hand, location given by different provinces has a significant role in determining different TCPL in the country. On average, each person is expected to spend US\$99.44 per month (US\$3.31 per person per day) for a living. This figure is far from truth for Matabeleland North and Matabeleland South where each person requires US $\$ 114.48$ per month (US\$3.82 per person per day) and US\$109.60 per month (US\$3.65 per person per day) respectively. Ideally, these two provinces experience a high cost of living whereas the inhabitants have little money to spend. Therefore, majority in these two provinces live below the TCPL pegged by ZIMSTAT. Harare, Bulawayo, Masvingo and Mashonaland West share the same TCPL. On average, each person from these provinces requires US\$98.59 per month (US\$3.29 per person per day) for a living. While Manicaland, Mashonaland East, Mashonaland Central and Midlands also share the same TCPL averaged at US $\$ 94.00$ per person per month (US\$3.13 per person per day). This last group needs some few monies per day to earn a living. Conclusively, The Total Consumption Poverty Line in Zimbabwe varies by province as prices vary from place to place and time has insignificant influence We would like to advise the government and Non - governmental organizations to put first priority to Matabeleland North which is most hit by poverty by introducing sustainable development projects and direct financial assistance,
Matabeleland South province is the next province to consider when mitigating or reducing poverty in the country. We suggest agrarian activities to be the best in this province but people need to be taught about small grain farming that endure little rainfall since most of the area receives little or no rainfall. Harare, Bulawayo and others are much better in terms of consumable and non - consumable prices of goods, hence poverty is not that devour even though some of the districts are on the worst side.

\section{References}

[1] Zimbabwe National Statistics Agency (ZIMSTAT), 2013. Poverty and Poverty Datum Line Analysis in Zimbabwe 2011/12. Website: www.zimstat.co.zw.

[2] World Bank 2001. World Development Report 2000/2001: Attacking Poverty. Oxford University Press, New York, USA.

[3] Asare, O.M.S., 2011. How poverty is a fortress without drawbridges and why we must build bridges. Masters Dissertation. UMI Dissertation Publishing, ProQuest. USA.

[4] Namara, R.E., Hanjra, M.A., Castillo, G.E., Ravnborg, H.M., Smith, L., and Koppen, B., 2010. Agricultural water management and poverty linkages. Agricultural Water Management. 97, 520-527.

[5] Saunyama, T.C. 2014. The Contribution of Informal Sector Trade to Poverty Reduction in Rusape, Zimbabwe. Masters Dissertation. University of Pretoria. South Africa.

[6] Chambers, R., 1988. Poverty in India: Concepts, Research and Reality. Discussion Paper 241. Institute of Development Studies, University of Sussex, U.K.

[7] World Bank 2008. Voices of the Poor. Website: http://go.worldbank.org

[8] Smith, G. 2004. US Aid to Africa. Review of African Political Economy 31, (102), 698-703.

[9] Siphambe, H.K. 2003. Dimensions and measures to reduce poverty in Botswana. Botswana Journal of African Studies 17, (2).

[10] Magombeyi, M.S., Taigbenu, A.E. and Barron, J., 2013. Rural poverty and Food insecurity mapping at district level for improved agricultural water management in the Limpopo River Basin. Colombo, Sri Lanka: CGIAR Challenge Programon Water and Food (CPWF). 54pp. (CPWF Research for Development (R4D) Series6).

[11] Booysen, F., S. Van DerBerg, R., Burger, M., Von Maltitz, and Rand, G., 2005. Using an asset index to assess trends in poverty in seven sub-Saharan African countries. Paper presented at the Conference on Multidimensional Poverty hosted by the International Poverty Center of the United Nations Development Program (UNDP), 29-31 August 2005. Brasilia, Brazil.

[12] Tarp, F., Simler, K., Matusse, C., Heltberg, R., and Dava, G., 2002. The Robustness of Poverty Profiles Reconsidered. Food Consumption and Nutrition Division of the International Food Policy Research Institute. Discussion Paper No.124.

[13] Sullivan, C., 2002. Calculating a water poverty index. World Development 30, (7), 1195-1210. 
[14] World Bank 2013. Working for a World Free of Poverty. Website: http://data.worldbank.org/country/

[15] Beaudoin, S.M., 2007. Poverty in World History. Routledge, New York.

[16] Thurow, R., and Kilman, S., 2009. Enough. Public Affairs. Philadelphia.

[17] Nyathi, D. 2012. An Evaluation of Poverty Alleviation Strategies Implemented by Non-Governmental Organizations (NGOs) in Zimbabwe: A Case of Binga Rural District. Masters Dissertation. University of Fort Hare. South Africa.
[18] Mundau, M. 2013. The Impact of Donor-Funded Community Empowerment Projects on Poverty Alleviation: A Case of Selected Projects in Chiredzi District of Zimbabwe. Masters Dissertation. University of Fort Hare. South Africa.

[19] Zulu, L. 2013. Female Education Breaks the Cycles of Poverty: A Case study of Chikomba Rural District, Zimbabwe. Masters Dissertation. Nelson Mandela Metropolitan University. South Africa.

[20] Montgomery, D.C., 2001. Design and Analysis of Experiments, $5^{\text {th }}$ Edition. John Wiley \& Sons. New York. USA. 